modified acetylene breathing procedure utilizing mass spectrometer measurements. Aviation Space Environ Med 48:203

22. Tucker HJ, Murray JF 1973 Effects of end expiratory pressure on organ blood flow in normal and diseased dogs. J Appl Physiol 34:265

23. Watanabe S, Frank R 1975 Lung volumes, mechanics, and single-breath diffusing capacity in anesthetized cats. J Appl Physiol 38:1148

24. Wilcox RE, Hightower WL, Smith RV 1979 Post-hoc data analysis in biomedical research. Am Lab 11:32

25. Woolverton WC, Bryham KL, Staub NC 1978 Effect of positive pressure breathing on lung lymph flow and water content in sheep. Circ Res 42:550

\title{
Uterine Arterial and Venous Concentrations of Glucose, Lactate, Ketones, Free Fatty Acids, and Oxygen in the Awake Pregnant Guinea Pig
}

\author{
L. L. H. PEETERS, L. MARTENSSON, B. K. VAN KREEL, AND H. C. S. WALLENBURG \\ Department of Obstetrics and Gynecology, Erasmus University Medical School, Dr. Molewaterplein 50, 3015 GE \\ Rotterdam, The Netherlands
}

\begin{abstract}
The concentration differences across the pregnant uterus of glucose, lactate, ketoacids, free fatty acids (FFA), and oxygen were determined in 21 chronically catheterized guinea pigs. Polyvinyl catheters were inserted into one of the ovarian veins and the right carotid artery around the 50th day of pregnancy. Postoperative recovery of maternal substrate concentrations in this preparation was evaluated in five animals. Elevated hemoglobin and ketoacid concentrations persisted up to the 4th day after surgery in the awake animal. In 16 animals between 54 and 62 days gestation, arterial and venous blood samples were collected between the 4th and 13th postoperative days. Arteriovenous substrate differences across the pregnant uterus (means \pm SD) were as follows: glucose, 0.87 $\pm 0.22 \mathrm{mM}$; lactate, $0.31 \pm 0.11 \mathrm{mM}$; and oxygen $4.77 \pm$ $0.58 \mathrm{mM}$. There was no significant difference for ketoacids. In 10 animals, plasma FFA concentrations were determined. In nine animals, the arterial concentration was higher suggesting a net uptake of FFA by the pregnant uterus. Lactate production by the uterus accounted for approximately $18 \%$ of uterine glucose uptake if glucose is assumed to be the only source of uterine lactate production. The mean glucose/oxygen quotient across the uterus corrected for lactate output was $0.92 \pm 0.34$. It is concluded that glucose is a major metabolic substrate for the nearterm uterus in the pregnant guinea pig and can account for most of the uterine oxygen consumption. (Pediatr Res 18:1172-1175, 1984)
\end{abstract}

\section{Abbreviations}

FFA, free fatty acids

IVC, inferior vena cava

UBF, uteroplacental blood flow

Received November 25, 1983; accepted April 20, 1984.

Requests for reprints may be addressed to Dr. L. L. H. Peeters, Dept. of Obstetrics and Gynecology, Erasmus University Medical School, Ee 2283, Dr. Molewaterplein 50, 3015 GD Rotterdam, The Netherlands.
Most of our knowledge of uterine metabolism in pregnancy is derived from experimental studies in ruminants. Only recently has it become technically feasible to perform cardiovascular and metabolic studies in chronically instrumented small mammals, such as the rat (6), the guinea pig (12), and the rabbit (7). Reproduction in these animals differs from that in the sheep with respect to several important variables, such as gestational length, placentation, litter size, fetal growth rate and fetal body composition. For this reason, it may be of interest to repeat in these species physiologic studies performed in pregnant ruminants. Among small mammals, the guinea pig is remarkable in that it produces a relatively large fetal mass with a high fat content ( $10 \%$ as compared with $2 \%$ in the fetal lamb) imposing an important metabolic drain upon the mother (1). We have developed a technique which allows measurement of uterine arterial and venous concentrations of various substrates in the unstressed, awake pregnant guinea pig (14). The present report describes the arteriovenous concentration differences for glucose, lactate, ketoacids, FFA, and oxygen obtained in this model.

\section{MATERIALS AND METHODS}

Twenty-one pregnant albino guinea pigs, bred in our own laboratory facility, were used in this study. The first day of pregnancy was defined as the second day of the opening of the vaginal membrane, provided the breeding was successful. From the 30th day until after completion of the experiments, the animals were kept in individual cages in a controlled environment $\left(19^{\circ} \mathrm{C}, 50 \%\right.$ humidity) with a $13: 11$-light/dark cycle. They were fed commercial guinea pig pellets, hay, and water ad libitum. Twice weekly, vitamin $\mathrm{C}$ and once weekly vitamin $\mathrm{E}$ were added to the drinking water.

Between 48 and 52 days gestation, the animals were anesthesized with ketamine $\mathrm{HCl}\left(30 \mathrm{mg} \cdot \mathrm{kg}^{-1} \mathrm{SC}\right)$ and xylazine $(3 \mathrm{mg}$. $\mathrm{kg}^{-1}$ intramuscular). Using aspectic techniques, a polyvinyl catheter (Bolab Inc., Derry, NH; o.d./i.d., 0.80:0.40 mm) was inserted into a carotid artery and advanced into the ascending aorta. A polyethylene "guide catheter" (Talas, Ommen, Holland; o.d./ i.d., 1.27:0.86 mm) was advanced retrogradely under fluoroscopy from the right jugular vein into the IVC to approximately $1 \mathrm{~cm}$ 
above the renal veins. A polyvinyl catheter (Bolab Inc.; o.d./i.d., 0.64:0.28 $\mathrm{mm}$ ) was passed through this guide catheter and advanced about $3 \mathrm{~cm}$ beyond its tip. The technique for insertion of this venous double-catheter has been described in detail elsewhere (14). Both catheters were tunneled subcutaneously and exteriorized between the shoulder blades. During the $1 \frac{1 / 2-2}{h}$ usually required for surgery, the animal received 500 units of heparin IV and $25 \mathrm{ml}$ of glucose $5 \%$ SC. Both catheters were filled with a heparinized saline solution and only the arterial catheter was flushed with saline every 2-3 days. No antibiotics were given after surgery.

In each of the 21 animals, a single experiment was planned between the 2 nd and 13 th post-operative days. The day before the experiment the animal was sedated with Brietal (1 mg IV). The inner venous catheter was removed from the IVC, cleaned with $70 \%$ ethanol, and reinserted through the guide catheter. Under fluoroscopic vision, the tip was advanced approximately $2 \mathrm{~cm}$ into one of the ovarian veins. The procedure, performed while the animal's back was slightly stretched, usually required less than $10 \mathrm{~min}$. Weight gain, behavior, and food intake were not affected by this procedure. On the next day, three sets of arterial and venous samples with a total volume of $6 \mathrm{ml}$ were obtained with an interval of 15 to 30 min between 1000 and $1200 \mathrm{~h}$. Concentrations of glucose, lactate, and ketoacids in whole blood were determined by standard enzymatic methods after perchloric acid precipitation (2). In 10 animals, plasma levels of FFA were determined by the colorimetric method as described by Laurell and Tibbling (10).

The oxygen content was calculated from the Hb concentration, the oxygen saturation ( $\mathrm{OSM}_{2}$ apparatus, Radiometer, Copenhagen), and the $\mathrm{PO}_{2},(\mathrm{ABL} 3$ Radiometer, Copenhagen) using the equation: $\left[\mathrm{O}_{2}\right]$ in $\mathrm{mM}=0.006206[\mathrm{Hb}](\mathrm{g} \%) \times \mathrm{O}_{2}$ saturation $(\%)+0.00136 \mathrm{Po}_{2}(\mathrm{~mm} \mathrm{Hg})$. Metabolic quotients were calculated by means of the following equation:

$$
\frac{[\mathrm{A}-\mathrm{V}] \text { substrate }(\mathrm{mM}) \times K}{[\mathrm{~A}-\mathrm{V}] \text { oxygen }(\mathrm{mM})}
$$

where $[\mathrm{A}-\mathrm{V}]$ substrate represents the arteriovenous concentration difference of each substrate measured and [A-V] oxygen, the simultaneously measured arteriovenous oxygen content difference. The constant $K$ indicates the number of moles of oxygen required for complete oxidation of $1 \mathrm{~mol}$ of substrate. Values of $K$ are 6 and 3 for glucose and lactate, respectively.

Data are presented as means \pm SD throughout, unless otherwise stated. Differences between groups were evaluated by paired Student's $t$ test, whereas the arteriovenous concentration differences for ketoacids and free fatty acids were evaluated using the Wilcoxon signed rank test. A $p$ value of less than 0.05 (twosided) was considered significant.

\section{RESULTS}

No significant difference could be demonstrated between paired first, second, and third values of each variable obtained in a single sampling session. For this reason, the mean of the three values obtained in each individual animal was used for statistical evaluation.

Five animals (group A) were sampled before and 16 animals (group B) after the fourth postoperative day. Group A animals had higher arterial concentrations of hemoglobin (Fig. 1), oxygen, and ketoacids (Table 1). However, the concomitant arteriovenous concentration differences across the uterus were comparable between the two groups. Only group B animals were included in the subsequent analysis. The gestational age in these 16 animals ranged from 54 to 61 days. Total litter weight and the fetal fraction of total maternal weight ranged from 125 to $419 \mathrm{~g}$ and from 15 to $32 \%$, respectively. The wide range in litter weight was a result of the differences in fetal number in each litter (two to six fetuses).

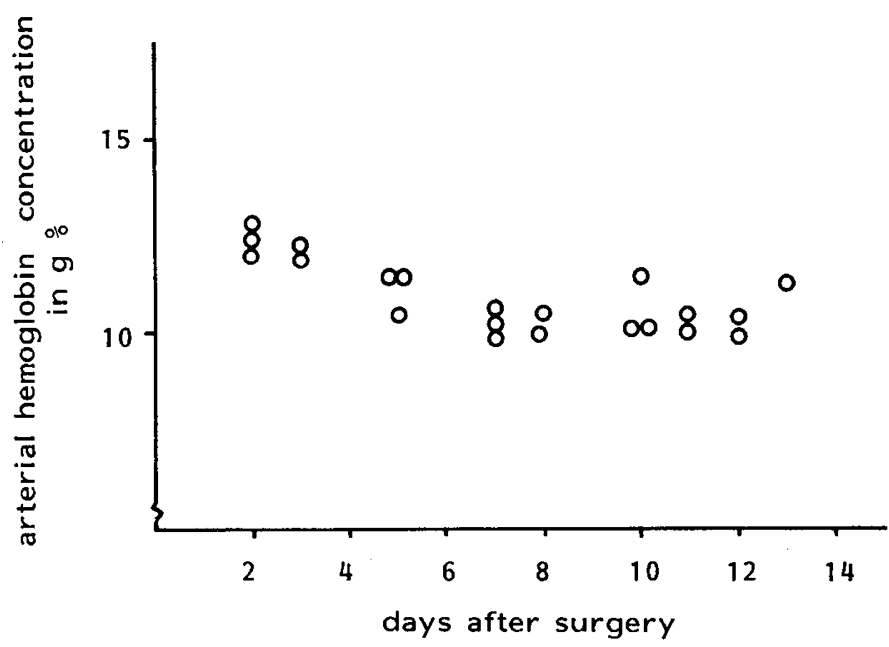

Fig. 1. Relationship between arterial hemoglobin concentration and length of postsurgical recovery. Each data point represents the mean values of these observations in one animal.

Table 1. Arterial concentrations of metabolic substrates and oxygen in animals studied before (group $A, n=5$ ) and after (group $B, n=16$ ) the 4th postoperative day

\begin{tabular}{lcc}
\hline & Group A & Group B \\
\hline Hemoglobin $(\mathrm{g} \%)$ & $12.3 \pm 0.4$ & $10.6 \pm 0.8$ \\
Oxygen $(\mathrm{mM})$ & $7.63 \pm 0.36$ & $6.55 \pm 0.48$ \\
& & \\
Glucose $(\mathrm{mM})$ & $4.58 \pm 0.47$ & $4.55 \pm 051$ \\
Lactate $(\mathrm{mM})$ & $1.37 \pm 0.42$ & $1.11 \pm 0.31$ \\
& & \\
$\beta$-OH-butyrate $(\mu \mathrm{M})$ & $189 \pm 124$ & $85 \pm 24$ \\
Acetoacetate $(\mu \mathrm{M})$ & $148 \pm 72$ & $70 \pm 22$ \\
\hline
\end{tabular}

The arteriovenous concentration differences across the uterus for glucose, lactate, ketoacids, FFA, and oxygen are listed in Table 2. The concentration differences were not significant for the ketoacids but significant for the FFA $(p<0.05)$ although there was a large variability between animals. The glucose/ oxygen quotient across the uterus was $1.11 \pm 0.31$. About $17 \%$ of uterine glucose uptake was needed to account for the uterine lactate output assuming all uterine lactate output originated from uterine glucose supply. Correction for this lactate output reduces the glucose/oxygen quotient to $0.92 \pm 0.34$. The variation observed in arterial concentrations of glucose, lactate, ketoacids, and FFA did not correlate with concomitant arteriovenous concentration differences across the uterus.

\section{DISCUSSION}

In the pregnant guinea pig, substrate concentrations are affected by surgical stress and anesthesia (16). The data summarized in Table 1 confirm the results reported by Sparks and associates (16) with regard to the rapid postsurgical normalization of glucose levels and the protracted elevation of ketoacids. In addition, we found that arterial $\mathrm{Hb}$ concentrations on the first 3 postsurgical days were approximately $15 \%$ higher than values collected after at least 3 full days of recovery (Fig. 1). It is likely that the elevated $\mathrm{Hb}$ levels reflect hemoconcentration which may be due to a decreased water intake in the immediate postoperative period. These data emphasize the dangers of drawing physiologic conclusions from studies in the chronically instrumented pregnant guinea pig performed before the 4th postsurgical day.

Blood samples in this study were collected around the 59th day of pregnancy. Our arterial substrate concentrations were comparable with those reported previously for this species for a similar gestational age (16). To our knowledge, only one study 
Table 2. Arterial concentrations and arteriovenous concentration differences across the uterus of the substrates and oxygen for each of the 16 guinea pigs

\begin{tabular}{|c|c|c|c|c|c|c|c|c|c|c|c|c|}
\hline \multicolumn{7}{|c|}{ Arterial concentrations } & \multicolumn{6}{|c|}{ Arteriovenous concentration difference across the uterus } \\
\hline $\begin{array}{l}\text { Animal } \\
\text { num- } \\
\text { ber }\end{array}$ & $\begin{array}{l}\text { Oxygen } \\
(\mathrm{mM})\end{array}$ & $\begin{array}{c}\text { Glucose } \\
(\mathrm{mM})\end{array}$ & $\begin{array}{l}\text { Lactate } \\
(\mathrm{mM})\end{array}$ & $\begin{array}{c}\beta \text {-OH-butyrate } \\
(\mu \mathrm{M})\end{array}$ & $\begin{array}{c}\text { Acetoacetate } \\
(\mu \mathrm{M})\end{array}$ & $\begin{array}{c}\text { Free fatty } \\
\text { acids } \\
(\mu \mathrm{M})\end{array}$ & $\begin{array}{c}\text { Oxygen } \\
(\mathrm{mM})\end{array}$ & $\begin{array}{c}\text { Glucose } \\
(\mathrm{mM})\end{array}$ & $\begin{array}{l}\text { Lactate } \\
(\mathrm{mM})\end{array}$ & $\begin{array}{c}\beta \text {-OH-butyrate } \\
(\mu \mathrm{M})\end{array}$ & $\begin{array}{l}\text { Acetoacetate } \\
(\mu \mathrm{M})\end{array}$ & $\begin{array}{c}\text { Free fatty } \\
\text { acids } \\
(\mu \mathrm{M})\end{array}$ \\
\hline 1 & 6.47 & 4.65 & 0.93 & 70 & 87 & 600 & 4.25 & 0.78 & -0.31 & 13 & 18 & 30 \\
\hline 2 & 7.11 & 5.09 & 0.79 & 104 & 117 & & 5.14 & 0.97 & -0.44 & 0 & 5 & \\
\hline 3 & 7.65 & 4.37 & 0.64 & 39 & 32 & 370 & 4.92 & 0.71 & -0.42 & -2 & 2 & 37 \\
\hline 4 & 6.42 & 4.76 & 1.21 & 100 & 64 & 410 & 4.62 & 1.31 & -0.32 & 8 & 9 & 30 \\
\hline 5 & 6.44 & 4.71 & 0.86 & 98 & 65 & & 4.80 & 0.93 & -0.29 & 19 & 25 & \\
\hline 6 & 6.37 & 4.79 & 1.03 & 97 & 61 & 340 & 4.07 & 0.63 & -0.42 & 8 & -24 & \\
\hline 7 & 5.83 & 4.60 & 1.20 & 49 & 49 & 670 & 4.24 & 0.90 & -0.18 & -1 & 16 & 80 \\
\hline 8 & 6.11 & 5.69 & 1.06 & 62 & 71 & 303 & 4.64 & 0.69 & -0.22 & 2 & 4 & 53 \\
\hline 9 & 6.41 & 3.92 & 1.56 & 104 & 95 & & 5.15 & 0.75 & -0.47 & -3 & -17 & \\
\hline 10 & 6.32 & 4.29 & 1.37 & 63 & 62 & 235 & 4.99 & 0.80 & -0.39 & -6 & -1 & -35 \\
\hline 11 & 6.23 & 4.29 & 1.88 & 92 & & 565 & 4.95 & 1.31 & -0.22 & 11 & & 165 \\
\hline 12 & 6.48 & 3.95 & 0.93 & 95 & & & 4.84 & 1.05 & -0.12 & 6 & & \\
\hline 13 & 6.12 & 5.10 & 1.13 & 117 & 58 & 665 & 3.50 & 0.87 & -0.17 & 10 & -22 & 85 \\
\hline 14 & 7.13 & 4.32 & 0.92 & 109 & 84 & 270 & 5.56 & 0.58 & -0.35 & -8 & 11 & 10 \\
\hline 15 & 7.26 & 3.72 & 1.20 & 71 & & 600 & 5.89 & 0.81 & -0.28 & 5 & & 240 \\
\hline 16 & 6.44 & & & & & & 4.74 & & & & & \\
\hline Median & 6.43 & 4.60 & 1.06 & 95 & 68 & 410 & 4.82 & 0.81 & -0.31 & 5 & 5 & 45 \\
\hline Mean & 6.55 & 4.55 & 1.11 & 85 & 70 & 469 & 4.77 & 0.87 & -0.31 & & & 70 \\
\hline SD & 0.48 & 0.51 & 0.31 & 24 & 22 & 169 & 0.58 & 0.22 & 0.11 & & & 80 \\
\hline
\end{tabular}


has been reported of arteriovenous substrate differences across the pregnant uterus of the awake guinea pig (S. M. Block, J. W. Sparks, R. L. Johnson, and F. C. Battaglia, manuscript submitted to Pediatric Research). That study was performed around the 45 th day of gestation, and comparison with our results indicates a striking difference in glucose and oxygen extraction values. In the present study (Table 2), mean uterine glucose extraction was $19 \%$ and oxygen extraction $73 \%$. In contrast Block et al. (manuscript submitted) reported values of 12 and $40 \%$, respectively, Although differences in methodology, direct versus retrograde catheterization, could play a part, the difference in extraction rates also could be attributed to the gestational age of the animals studied, 59 and 45 days, respectively.

UBF was calculated for mid- and late pregnancy in the guinea pig using the raw data reported previously $(11,13)$. Between these gestational ages, there is an important fall in UBF per $\mathrm{kg}$ of uterus and conceptus: Between 40 and 50 days, UBF is approximately $250 \mathrm{ml} \cdot \mathrm{min}^{-1} \mathrm{~kg}^{-1}$ and between 55 and 60 days it is approximately $160 \mathrm{ml} \cdot \mathrm{min}^{-1} \mathrm{~kg}^{-1}$. The high extraction rates for glucose and oxygen in all of our animals between 54 and 61 days (Table 1) suggest that an increase in these extraction rates occurs between the 45th and 54th day of pregnancy, coinciding with the fall in relative UBF. A high extraction rate in the nearterm period may be an important compensatory mechanism in the guinea pig to maintain uterine glucose and oxygen uptakes per unit weight in the fact of reduced relative UBF.

In several species, including the midpregnant guinea pig (Block et al., manuscript submitted), the pregnant uterus has been shown to produce lactate under aerobic conditions $(4,5,7)$. The mean lactate/oxygen quotient in our study was -0.19 which is lower than the figure of -0.40 obtained by Block and associates. The resulting higher glucose/oxygen quotient (corrected for lactate output) across the uterus (0.92 versus 0.80$)$ in our study suggests that a higher fraction of maternal glucose is retained by the near-term uterus in order to satisfy the increasing demands for carbon of the conceptus. Our method of measuring arteriovenous concentration differences implies that differences for substrates with a low extraction rate are subject to large variability. This methodological problem applies to the ketoacids and the FFA. Ketoacids, palmitate, and linoleic acid have been demonstrated to cross the guinea pig placenta $(8,9,15)$. In our study, we were unable to demonstrate a significant arteriovenous concentration difference for the ketoacids, possibly because of the low arterial concentrations in the fed state (Block et al., manuscript submitted). In nine of 10 animals, FFA concentrations were higher in the artery suggesting FFA uptake by the late pregnant uterus of the guinea pig. With different methodology, it has been demonstrated that the uterine FFA uptake in the pregnant guinea pig appears to exceed the requirements needed for incorporation in fetal lipids (9). However, the large variation in the arteriovenous concentration differences in the present study does not allow quantitative conclusions about uterine uptake.

In conclusion, our data on arteriovenous concentration differences across the uterus in the guinea pig indicate that: 1) uterine substrate uptake in the near-term period is characterized by high extraction rates for glucose and oxygen; 2) the net uterine glucose uptake is so large that it could fuel most of the uterine oxidative metabolism; 3) ketoacids are not taken up in significant amounts by the uterus in late pregnancy; and finally 4) FFA are taken up by the uterus, but their role as a metabolic substrate for the conceptus remains to be assessed.

\section{REFERENCES}

1. Battaglia FC, Meschia G 1981 Foetal and placental metabolism: their interrelationship and impact upon maternal metabolism. Proc Nutr Soc 40:99

2. Bergmeyer HU (ed) 1974 Methods of Enzymatic Analysis, vols 2-4. Academic Press, Inc, New York

3. Deleted in proof.

4. Burd LI, Jones MD, Simmons MA, Makowski EL, Meschia G, Battaglia FC 1975 Placental production and fetal utilization of lactate and pyruvate. Nature 254:710

5. Comline RS, Silver M 1976 Some aspects of fetal and uteroplacental metabolism in cows with indwelling umbilical and uterine vascular catheters. $\mathbf{J}$ Physiol (Lond) 260:571

6. Gilbert M, Pegorier JP 1981 Substrate concentration changes during pregnancy in the conscious rat. J Dev Physiol 3:343

7. Gilbert M, Bouisset M, Hauguel S 1984 Uterine blood flow and substrate uptake in conscious rabbit during late gestation. Am J Physiol, in press

8. Hersfield MS, Nemeth AM 1968 Placental transfer of free palmitic and linoleic acids in the guinea pig. J Lipid Res 9:460

9. Jones CT 1976 Lipid metabolism and mobilization in the guinea pig during pregnancy. Biochem J 156:357

10. Laurell S, Tibbling G 1967 Colorimetric microdetermination of free fatty acids in plasma. Clin Chem Acta 16:57

11. Myers SA, Sparks JW, Makowski EL, Meschia G, Battaglia FC 1982 Relationship between placental blood flow and placental and fetal size in the guinea pig. Am J Physiol 243:H404

12. Peeters LLH, Grutters G, Martin CB 1980 The distribution of cardiac output in the unstressed pregnant guinea pig. Am J Obstet Gynecol 138:1177

13. Peeters LLH. Sparks JW, Grutters G, Girard J, Battaglia FC 1982 Uteroplacental blood flow during pregnancy in chronically catheterized guinea pigs. Pediatr Res 16:716

14. Peeters LLH, Wallenburg HCS 1983 Technique for chronic blood sampling from the ovarian vein in the pregnant guinea pig. Biol Res Preg Perinatol $5: 118$

15. Shambaugh GE III, Mrozak SC, Freinkel N 1977 Fetal fuels. I. Utilization of ketones by isolated tissues at various stages of maturation and maternal nutrition during late pregnancy. Metabolism 26:623

16. Sparks JW, Pegorier JP, Girard J, Battaglia FC 1981 Substrate concentration changes during pregnancy in the guinea pig studied under unstressed steady state conditions. Pediatr Res 15:1340 